Pesq. Vet. Bras. 36(9):905-911, setembro 2016 DOI: 10.1590/S0100-736X2016000900018

\title{
Atividade antisséptica do óleo essencial de Lippia origanoides Cham. (Alecrim-pimenta) na presença de leite bovino ${ }^{1}$
}

\author{
Anna Christina de Almeida ${ }^{2 *}$, Rodrigo Pereira Morão², Ernane Ronie Martins ${ }^{2}$, \\ Francine Souza Alves da Fonseca², Cintya Neves de Souza ${ }^{2}$, João Paulo Bicalho \\ Prates $^{2}$, Fábio Dias de Oliveira ${ }^{2}$ e Lívia Mara Vitorino da Silva ${ }^{2}$
}

\begin{abstract}
Almeida A.C., Morão R.P., Martins E.R., Fonseca F.S.A., Souza C.N., Prates J.P.B., Oliveira F.D. \& Silva L.M.V. 2016. [Antiseptic activity of the essential oil of Lippia origanoides in the presence of bovine milk.] Atividade antisséptica do óleo essencial de Lippia origanoides Cham. (Alecrim-pimenta) na presença de leite bovino. Pesquisa Veterinária Brasileira 36(9):905-911. Universidade Federal de Minas Gerais, Campus Montes Claros, Av. Universitária 1000, Montes Claros, MG 39404-547, Brazil. E-mail: aca2006@ica.ufmg.br

This study aimed to determine the antiseptic activity of the essential oil of Lippia origanoides in the presence of bovine milk. The essential oil chemical composition was determined by gas chromatography-mass spectrometry (CG EM) 53 compounds were detected, of which 16 were identified ( $>0.1 \%$ total area). The carvacrol $(32.7 \%)$, p-cymene $(23 \%)$, thymil methyl ether (10.03\%), caryophyllene $(7.98 \%)$ and $\gamma$-terpinene $(5.40 \%)$ were the most abundant components. The minimum inhibitory concentration for Staphylococcus aureus ATCC 25923 and Escherichia coli ATCC 8739 was $60 \mathrm{uL} / \mathrm{mL}$, as for this Salmonella Choleraesuis ATCC 35640 was $90 \mathrm{uL} / \mathrm{mL}$. The minimum bactericidal concentration was $120 \mu \mathrm{L} /$ $\mathrm{mL}$ for all three bacteria. We evaluated the antiseptic activity of the essential oil in the concentration of $120 \mu \mathrm{L} / \mathrm{mL}$ in the presence of bovine milk for the same bacterial strains. The oil under study It showed an inhibitory effect of growth of the strains in different action times $(\mathrm{p}<0.05)$. S. aureus showed higher inhibition rates after 5 min of contact and $E$. coli and Salmonella Choleraesuis after $15 \mathrm{~min}$. The essential oil Lippia origanoides proved to be a natural antimicrobial potential even in the presence of organic matter consists of a complex nutritional matrix is bovine milk.
\end{abstract}

INDEDX TERMS: Antiseptic activity, essential oil, Lippia origanoides, bovine milk, carvacrol, thymol, natural antimicrobials, inhibitory effect.

RESUMO.- Objetivou-se determinar atividade antisséptica do óleo essencial de Lippia origanoides na presença de leite bovino. A composição química do óleo essencial de alecrim pimenta foi determinada por cromatografia gasosa acoplada à espectrometria de massas (CG-EM), sendo detectados 53 compostos, dos quais 16 foram identificados $(>0,1 \%$ área total). 0 carvacrol (32,7\%), p-cimeno (23\%), timilmetil éter, cariofileno $(7,98 \%)$ e o $\gamma$-terpineno $(5,40 \%)$ foram os componentes mais abundantes. A concentração inibitória mínima para Staphylococcus aureus ATCC 25923 e E. coli ATCC 8739 foi de $60 \mu \mathrm{L} / \mathrm{mL}$, enquanto para Salmonella

\footnotetext{
${ }^{1}$ Recebido em 12 de dezembro de 2015.

Aceito para publicação em 27 de maio de 2016.

${ }^{2}$ Universidade Federal de Minas Gerais (UFMG), Campus Montes Claros, Av. Universitária 1000, Montes Claros, MG 39404-547, Brasil. *Autor para correspondência: aca2006@ica.ufmg.br
}

Choleraesuis ATCC 35640 foi de $90 \mu \mathrm{L} / \mathrm{mL}$. A concentração bactericida mínima foi de $120 \mu \mathrm{L} / \mathrm{mL}$ para as três bactérias. Avaliou-se a atividade antisséptica do óleo essencial na concentração de $120 \mu \mathrm{L} / \mathrm{mL}$ na presença de leite bovino sobre as mesmas cepas bacterianas. 0 óleo em estudo apresentou efeito inibitório do crescimento das cepas em diferentes tempos de ação $(\mathrm{p}<0,05)$. $S$. aureus apresentou maiores índices de inibição após 5 min de contato e Escherichia coli e Salmonella Choleraesuis após 15 min. 0 óleo essencial de alecrim-pimenta revelou ser um potencial antimicrobiano natural, mesmo na presença de matéria orgânica constituída de uma matriz nutricional complexa que é o leite bovino.

TERMOS E INDEXAÇÃO: Atividade antisséptica, óleo essencial, $L i$ ppia origanoides, alecrim-pimenta, leite bovino, carvacrol, timol, antimicrobianos naturais, efeito inibitório. 


\section{INTRODUÇÃO}

A implantação de programas de controle de mastite bovina está relacionada com a redução dos fatores negativos que essa enfermidade provoca na cadeia produtiva do leite, como queda de produção, menor rendimento dos produtos lácteos, diminuição do tempo de prateleira, aumento dos custos com medicamentos, honorários profissionais, descarte de leite durante o período de tratamento e de carência, perda de tetos e de animais (Langoni 2013).

0 uso de fármacos e produtos com atividade antimicrobiana e antisséptica em programas de controle é preocupante em todo o mundo, principalmente pela multirresistência desenvolvida por microrganismos, como também pela veiculação de resíduos para os alimentos e para o ambiente. Os óleos essenciais vêm sendo investigados, partindo da possibilidade de utilizá-los como produtos alternativos, com menor potencial tóxico, para aplicação na saúde humana e animal (Almeida et al. 2010).

A atividade biológica de óleos essenciais in vitro já é bastante conhecida frente a bactérias, leveduras e fungos, porém, as alterações que poderão ocorrer na atividade destes óleos na presença de matéria orgânica e em matrizes complexas de alimentos tais como gordura, proteína, atividade de água diversa, $\mathrm{pH}$ diverso e enzimas alimentares (Negi, 2012, Calo et al. 2015), ainda são pouco estudadas. Fatores relacionados com alterações das características sensoriais são citados na literatura (Calo et al. 2015, Pesavento et al. 2015).

Entre as plantas da flora Brasileira que produzem óleo essencial com potencial antimicrobiano e antisséptico promissor está Lippia origanoides Kunth (Verbenaceae) (Andrade et al. 2014, Oliveira et al. 2014, Guimarães et al. 2014, Queiroz et al. 2014) sendo o carvacrol e timol os compostos majoritários que apresentam características antimicrobianas (Sarrazin et al. 2012, Oliveira et al. 2014).

0 potencial uso deste óleo essencial como antimicrobiano e antisséptico em saúde e produção animal, já foi confirmado in vitro em bactérias isoladas de leite e outros alimentos de origem animal (Costa et al. 2011, Castro et al. 2011, Queiroz et al. 2014) , no entanto, pesquisas que avaliem a possível interferência de matéria orgânica na atividade ainda não foram publicadas.

Com o presente trabalho, determinou-se a composição química do óleo essencial de alecrim-pimenta cultivado na região Norte de Minas Gerais e estudou-se atividade antisséptica do mesmo frente a bactérias patogênicas na presença de leite bovino.

\section{MATERIAL E MÉTODOS}

Obtenção e preparo do óleo de alecrim pimenta. As folhas de alecrim-pimenta foram coletadas entre 9:00 e 10:00 horas da manhã (Melo et al. 2011) no período de janeiro a março de 2014, na reserva nativa do Instituto de Ciências Agrárias da Universidade Federal de Minas Gerais na cidade de Montes Claros/MG (coordenadas $16^{\circ} 40^{\prime} 51,5^{\prime \prime} \mathrm{S}$ e $43^{\circ} 50^{\prime} 32,1^{\prime \prime} \mathrm{W}$, altitude de $640 \mathrm{~m}$. Após a coleta, as folhas foram transferidas para sacos plásticos de polietileno e levadas ao Laboratório de Plantas Medicinais do ICA/UFMG para a secagem em estufa $\left(45^{\circ} \mathrm{C} \pm 2^{\circ} \mathrm{C}\right)$ com circulação forçada de ar (Falkenberg et al. 2007). 0 óleo essencial de alecrim-pimenta foi obtido por destilação por arraste de vapor em destilador piloto (Linax ${ }^{\circledR}$, modelo D20). Após três horas de extração, o óleo foi separado do hidrolato por partição líquido-líquido (Koketsu \& Gonçalves 1991). Posteriormente seco, com sulfato de sódio anidro, acondicionado em frascos âmbar estéreis sob refrigeração $\left(4-8^{\circ} \mathrm{C}\right)$

Análise cromatográfica. A análise da composição química para quantificação e identificação dos compostos presentes no óleo essencial, foram realizadas no laboratório de Química Instrumental do ICA-UFMG. A quantificação relativa dos constituintes majoritários foi realizada em cromatógrafo a gás GC 7820A equipado com detector de ionização em chamas (Agilent Technologies, Santa Clara, Estados Unidos) e coluna capilar HP-5 (Agilent Technologies, $30 \mathrm{~m}$ comprimento x 0,32 mm diâmetro interno $\mathrm{x}$ $0,25 \mu \mathrm{m}$ espessura do filme). 0 hélio $(99,9999 \%$ de pureza) foi utilizado como gás de arraste $\left(1 \mathrm{~mL} \mathrm{~min}^{-1}\right)$ e a amostras injetada $(1 \mu \mathrm{L})$ através do auto injetor na razão de split (1:5), mantido a $220^{\circ} \mathrm{C}$. A coluna cromatográfica inicialmente a $60^{\circ} \mathrm{C}$ foi aquecida a uma taxa de $3^{\circ} \mathrm{C} \mathrm{min}^{-1}$ até $240^{\circ} \mathrm{C}$, permanecendo a essa temperatura por $30 \mathrm{~min}$. Após a separação dos compostos a temperatura foi elevada até $300^{\circ} \mathrm{C}$ ( $3 \mathrm{~min}$ ) para limpeza do sistema.

A identificação dos compostos foi realizada por meio do cromatógrafo a gás GC7890A acoplado a espectrômetro de massa 5975C (Agilent Technologies, Santa Clara, Estados Unidos). Foi utilizada coluna capilar DB-5MS (30m x $0,25 \mathrm{~mm} \times 0,25 \mu \mathrm{m})$ e hélio $(99,9999 \%$ de pureza) como gás de arraste à taxa de $1 \mathrm{~mL}$ $\min ^{-1}$. A amostra $(1 \mu \mathrm{L})$ foi injetada no cromatógrafo a razão de split $1: 5$ e o injetor foi mantido a $220^{\circ} \mathrm{C}$. A coluna cromatográfica inicialmente a $60^{\circ} \mathrm{C}$ foi aquecida a $3^{\circ} \mathrm{C} \mathrm{min}^{-1}$ até $240^{\circ} \mathrm{C}$, a qual permaneceu a essa temperatura por 30 minutos. Posteriormente a temperatura foi elevada até $300^{\circ} \mathrm{C}$ por 3 minutos (post run). A temperatura da interface foi mantida a $240^{\circ} \mathrm{C}$ a ionização realizada com impacto de 70 e V com varredura de 30 a $600 \mathrm{~m} / z$. A identificação dos compostos foi realizada por comparação do espectro de massas com os espectros da biblioteca NIST MS 2.0 e da literatura (Adams, 2012). Calculou-se o índice de retenção relativo dos compostos a partir do tempo de retenção de uma mistura de n-alcanos (C7-C40, Sigma USA) 20ppm, split 1:100, segundo (Van Den Dool \& Kratz 1963).

Teste de atividade antimicrobiana. Para determinar a concentração inibitória mínima (CIM), foi utilizada solução preparada com $4360 \mu \mathrm{L}$ caldo BHI (Brain Heart Infusion) estéril, com $40 \mu \mathrm{L}$ de "Tween 80" e $600 \mu \mathrm{L}$ de óleo essencial, constituindo a concentração de $120 \mu \mathrm{L} / \mathrm{mL}$ de óleo de alecrim-pimenta. A partir dessa solução fez-se a macrodiluição do mesmo para aquisição das concentrações de 90, 60, 45 e $30 \mu \mathrm{L} / \mathrm{mL}$ do óleo de alecrim-pimenta (Andrade et al. 2014). Logo após adicionaram-se $50 \mu \mathrm{L}$ de inóculo dos microrganismos Staphylococcus aureus ATTCC 25923, Escherichia coli ATTCC 8739 e Salmonella Choleraesuis ATCC 35640, conforme recomendações de Brasil (2007) para avaliação de produtos sanitizantes e ou desinfetantes para uso na indústria de alimentos. Os inóculos foram preparados em salina estéril 0,9\%, padronizados utilizando-se a escala de McFarland a 0,5 , correspondendo a aproximadamente $1,5 \times 10^{8}$ unidades formadoras de colônias (UFC)/mL (CLSI 2012).

Como controle analisou-se a CIM das cepas em estudos utilizando as drogas ciprofloxacina e tetraciclina, conforme recomendação de CLSI (2012). Tubos com demais reagentes exceto o óleo essencial foram incluídos como controle da atividade do "Tween 80 ". Os tubos foram agitados em vortex para assegurar a homogeneização da solução com óleo e no decorrer do período de incubação certificou-se de que não ocorreu separação das fases, confirmando a solubilização. 0 teste foi realizado em triplicata para cada uma das três cepas e os tubos foram incubados a $37^{\circ} \mathrm{C}$ por 24 horas. Para o teste de concentração bactericida mínima (CBM) 
foi retirada uma alçada do conteúdo dos tubos do teste de CIM que não apresentaram turvação após as 24 horas de incubação e fez-se a inoculação em placas de Petri contendo meio Ágar para Contagem Padrão (PCA). Estas foram incubadas a $37^{\circ} \mathrm{C}$ por 24 horas. A CIM foi definida como a menor concentração do óleo que não permitiu o crescimento visível do microrganismo. A CBM foi definida como a menor concentração do óleo que não permitiu o crescimento visível na subcultura do microrganismo (CLSI 2012).

Teste de atividade antisséptica na presença de leite. Para determinação da atividade antisséptica adotou-se a metodologia do teste de suspensão na presença de matéria orgânica, descrita pelo Ministério da Agricultura, Pecuária e Abastecimento (Brasil 1993), modificados conforme descrito por Schuch et al. (2008). Para cada microrganismo, tubos de ensaio contendo solução-teste foram preparados com $9 \mathrm{~mL}$ de BHI e $1 \mathrm{~mL}$ de matéria orgânica constituída de leite em pó bovino desnatado Molico ${ }^{\circledR}$ reconstituído na proporção $20 \mathrm{~g}$ de leite $200 \mathrm{ml}$ de água destilada e este foi esterilizado em autoclave a $121^{\circ} \mathrm{C}$ por 20 minutos. Aos tubos foi acrescentado óleo essencial de alecrim-pimenta, preparando-se solução com concentração final $120 \mu \mathrm{L} / \mathrm{mL}$ de óleo essencial solubilizado em $40 \mu \mathrm{L}$ "Twen 80 ". $50 \mu \mathrm{L}$ de cada inóculo bacteriano correspondendo a 0,5 da escala de McFarland (CLSI 2012) foram inoculados nos tubos de ensaio e agitados vigorosamente em vórtex. Alíquotas de $100 \mu \mathrm{L}$ foram retiradas em intervalos de $0,5,10$, 30 e 60 min e inoculadas em superfície de placas de Petri contendo PCA, onde as colônias crescidas foram quantificadas após 24 horas de incubação a $37^{\circ} \mathrm{C}$ (APHA, 2001). A concentração do óleo utilizada neste teste foi a definida na CIM e CBM para todas as bactérias em estudo.

0 teste controle, sem o óleo, foi realizado nas mesmas condições citadas acima para compor o cálculo do índice de inibição de crescimento (II) (Schuch et al. 2008). Todo experimento foi realizado em triplicata. Realizou-se o controle de crescimento bacteriano das soluções teste e da matéria orgânica semeando-se alíquota de $100 \mu \mathrm{L}$ em tubo de ensaio contendo $5 \mathrm{~mL}$ de caldo infuso cérebro-coração e incubando-se a $37^{\circ} \mathrm{C}$ por 96 horas.

0 teste foi considerado válido quando o inóculo conteve entre $10^{5-6} \mathrm{UCF} / \mathrm{mL}$, conforme avaliado pela contagem das placas-controle. A contagem das placas foi realizada e calculando as médias de cada repetição e dos controles (APHA 2001). Transformação logarítmica em $\log (\mathrm{y}+1)$ foi realizada conforme recomendo por Sampaio (2002). O índice de inibição II foi calculado com a fórmula: $I I=1-(\log$ tratamento +1$)(\log \text { controle }+1)^{-1}($ Schuch et al. 2008).
Análise estatística. 0 desenho experimental seguiu o delineamento inteiramente casualisado com dois tratamentos (óleo essencial e água destilada) na presença de leite bovino em cinco tempos distintos $(0,5,15,30$ e 60 minutos), em triplicata, analisando-se isoladamente cada uma das três bactérias e com a variável dependente expressa em índice de inibição II. Estes dados foram submetidos à análise de variância e as médias foram comparadas pelo teste de Fisher Bonferoni $(\mathrm{p}<0,05)$. 0 índice de inibição médio observado em cada tempo comparando as três bactérias foi avaliado pelo teste de Tukey $(\mathrm{p}<0,001)$. Empregou-se a correlação de Pearson e regressão linear para avaliação do efeito do tempo sobre o índice de inibição de crescimento microbiano. As análises foram realizadas utilizando o Programa Estatístico R, versão 2.12.2.

\section{RESULTADOS}

\section{Caracterização do óleo essencial}

Foram detectados 53 compostos no óleo essencial, dos quais foi identificado o (10) carvacrol (32,7\%), (3) p-cimeno $(23 \%),(7)$ timilmetil éter $(10,03 \%),(11)$ cariofileno $(7,98 \%)$ e o (5) $\gamma$-terpineno (5,40\%), conforme Figura 1. A maior parte dos compostos identificados são monoterpenos oxigenado $(38,72 \%)$, seguida dos monoterpenos $(31,76 \%)$ e sesquiterpenos $(15,61 \%)$ e os demais correspondem aos sesquiterpenos funcionalizados ou outros grupos $(13,89 \%)$ (Quadro 1).

\section{Atividade antimicrobiana e antisséptica}

A CIM de $60 \mu \mathrm{L} / \mathrm{mL}$ foi obtida para Staphylococcus aureus e para Escherichia coli enquanto que para Salmonella Cholerae suis esta foi de $90 \mu \mathrm{L} / \mathrm{mL}$. A CBM obtida para $S$. aureus, E. coli e Salmonella Choleraesuis foi de $120 \mu \mathrm{L} / \mathrm{mL}$, valor superior aos obtidos para CIM de todos estes microrganismos.

$\mathrm{Na}$ avaliação da atividade antisséptica do óleo essencial na presença de matéria orgânica, observou-se diferença para os índices de inibição (II) em relação ao tempo zero, que foi controle do teste, para todos os microrganismos em análise $(\mathrm{p}<0,05)$ (Fig.2). Observou-se diferença significativa $(p<0,001)$ entre os índices de inibição em cada tempo comparando as três cepas bacterianas em estudo (Fig.3).

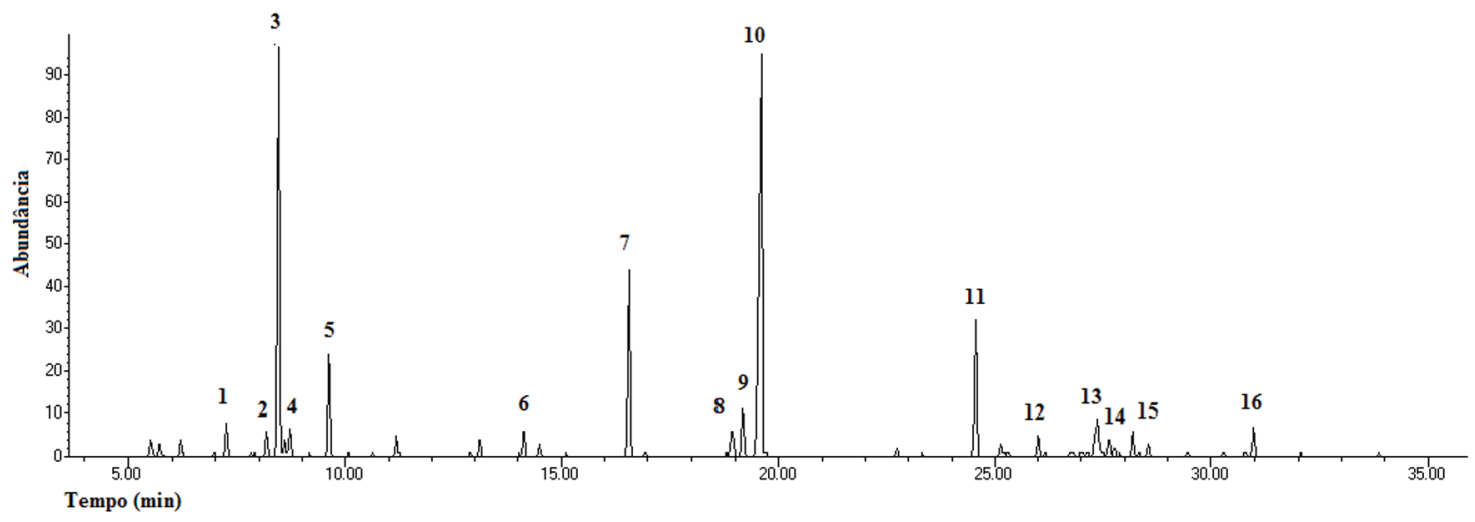

Fig.1. Componentes do óleo essencial de folhas do alecrim pimenta (Lippia origanoides HBK) coletados na reserva nativa do Instituto de Ciências Agrárias da UFMG, Montes Claros, MG, e identificados por cromatografia gasosa acoplado a espectrometria de massas (CG-EM). (1) Mirceno, (2) 4-Careno, (3) p-Cimeno, (4) 1,8-Cineol, (5) $\gamma$-Terpineno, (6) Borneol, (7) Timilmetil éter, (8) Acetato de Borneol, (9) Timol, (10) Carvacrol, (11) Cariofileno, (12) Humuleno, (13) Sesquiterpeno não identificado, (14) $\alpha$-Selineno, (15) $\beta$-Bisaboleno, (16) Óxido de cariofileno. 
Quadro 1. Compostos identificados no óleo essencial de alecrim pimenta (Lippia origanoides HBK). TR: tempo de retenção (min). IRLiteratura: índice de retenção relativo da literatura (Adams 2012). IRcalculado: índice de retenção calculado. \% relativa: área relativa dos compostos obtida na análise cromatográfica

\begin{tabular}{lccccc}
\hline $\mathrm{N}^{\circ}$ & $\mathrm{TR}$ & $\mathrm{IR}_{\text {literatura }}$ & IR $_{\text {calculado }}$ & Composto & \% relativa \\
\hline 1 & 7.24 & 988 & 991 & $\beta$-Mirceno & 1.87 \\
2 & 8.18 & 1001 & 1019 & Careno & 1.48 \\
3 & 8.46 & 1020 & 1027 & p-Cimeno & 23.00 \\
4 & 8.71 & 1026 & 1033 & 1,8-Cineol & 1.59 \\
5 & 9.62 & 1054 & 1059 & $\gamma$-Terpineno & 5.40 \\
6 & 14.13 & 1165 & 1173 & Borneol & 1.45 \\
7 & 16.57 & 1232 & 1230 & Timilmetil éter & 10.03 \\
8 & 18.92 & 1284 & 1285 & Acetato de borneol & 2.14 \\
9 & 19.17 & 1289 & 1291 & Timol & 2.96 \\
10 & 19.60 & 1298 & 1301 & Carvacrol & 32.70 \\
11 & 24.56 & 1408 & 1419 & Cariofileno & 7.98 \\
12 & 26.01 & 1436 & 1454 & Humuleno & 1.27 \\
13 & 27.38 & - & 1488 & Desconhecido & 3.73 \\
14 & 27.65 & 1498 & 1494 & $\alpha$-Selineno & 1.19 \\
15 & 28.19 & 1506 & 1508 & $\beta$-Bisaboleno & 1.42 \\
16 & 30.99 & 1582 & 1580 & Óxido de cariofileno & 1.71 \\
Monoterpenos & & & & 31,76 \\
Monoterpenos oxigenados & & & 38,72 \\
Sesquiterpenos & & & & 15,61 \\
Sesquiterpenos oxigenados & & & 1,71 \\
Outros & & & &
\end{tabular}

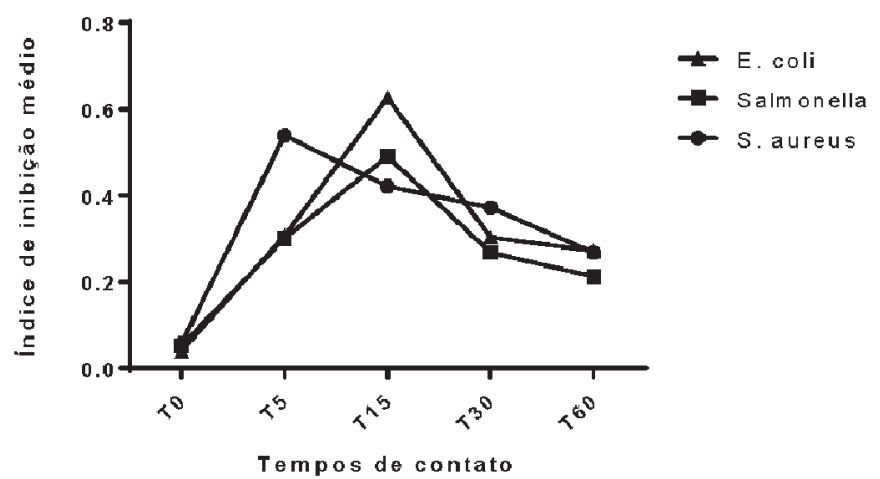

Fig.2. Médias de índice de inibição de crescimento microbiano para Staphylococcus aureus, Salmonella Choleraesuis e Escherichia coli pelo óleo essencial de alecrim pimenta na presença de leite bovino em diferentes tempos de contato.

Melhor resultado de inibição de crescimento pelo óleo foi observado frente ao microrganismo $S$. aureus onde o tempo de contato de 5 minutos foi suficiente para promover maior índice de inibição. Para E. coli e Salmonella Choleraesuis, foi necessário o tempo de 15 minutos de contato para se obter maior inibição de crescimento.

A correlação de Pearson entre o tempo de exposição de S. aureus (-0.01237), Salmonella Cholerae suis (0.03139) e E. coli (0.10478) ao óleo na presença do leite indicaram que com o aumento do tempo de exposição do óleo, houve menor crescimento bacteriano. 0 coeficiente de determinação estimado na analise de regressão linear $\left(R^{2}\right)$ foi de $0,000002 \%$, para $S$. aureus, $0,000011 \%$ para $E$. coli e de 0,000001\% para Salmonella Cholerae suis, o que confirma que há uma diferença entre as médias encontradas nos índices de inibição nos diferentes tempos. Assim, o tempo

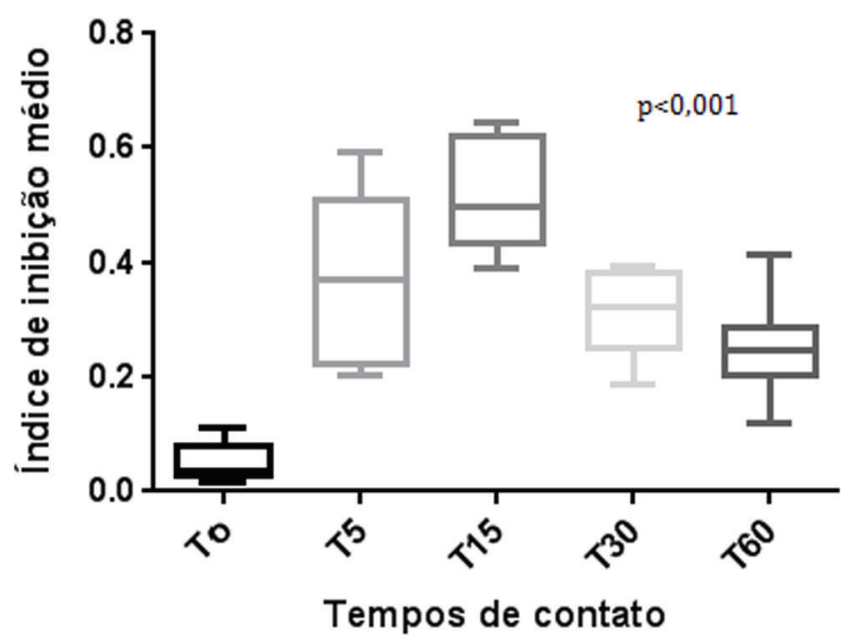

Fig.3. Comparação entre os índices de inibição de crescimento microbiano de Staphylococcus aureus, Salmonella Choleraesuis e Escherichia coli pelo óleo essencial de alecrim pimenta na presença de leite bovino em diferentes tempos de contato.

máximo para exposição aos óleos é de até 30 minutos, pois após esse tempo os índices de inibição de crescimento reduzem os valores, apesar de ainda serem distantes do tempo zero que foi o controle.

Os dados aqui apresentados são confirmados pelo teste de Fisher Bonferroni indicando que houve diferença significativa após a exposição ao óleo no tempo 15 minutos para E. coli e Salmonella Cholerae suis e de 5 minutos para S. aureus $(\mathrm{p}<0,05)$.

Quando analisada a redução do número médio de Log UFC, na presença do óleo, em relação ao tempo zero esta foi de 2,18993Log UFC para S. aureus no tempo de contato de 5 minutos, 2,343321 Log UFC para E. coli e 2,100343 Log UFC para Salmonella Cholerae suis, ambas no tempo 15 minutos. Observou-se também redução significativa $(\mathrm{p}<0,05)$ no número médio de Log UFC entre o controle e tratamento com óleo nos diferentes tempos para as três cepas em estudo.

\section{DISCUSSÃO}

Estudos realizados com óleo essencial de alecrim-pimenta provenientes da mesma área de reserva nativa do ICAUFMG na região Norte de Minas Gerais apresentaram resultados semelhantes quanto aos compostos majoritários, (10) carvacrol, seguido de (03) p-cimeno, (7) timilmetil éter, (11) cariofileno e o $\gamma$-terpineno (05) (Costa et al. 2011, Castro et al. 2011, Andrade et al. 2014, Queiroz et al. 2014). Resultados relatados por autores em outras regiões do estado de Minas Gerais também são condizentes com os aqui descritos, ainda que os compostos tenham sido encontrados em percentual variável. Teixeira et al. (2014), com avaliação de óleo essencial de alecrim-pimenta da região de Lavras, MG, corroboram com os aqui descritos, sendo os componentes majoritários carvacrol $(41,51 \%)$, p-cimeno (18.36\%), $\gamma$-terpineno $(17,03 \%)$ e timol $(4,86 \%)$. Guimarães et al. (2014), analisaram diferentes partidas de óleo proveniente da região sul de Minas Gerais e estas apresentaram como constituintes majoritários o carvacrol $(26,44 \%)$ e o 1,8 -cineol $(22,63 \%)$. Lima et al. (2011) 
encontraram o carvacrol (31,68\%), p-cimeno $(19,58 \%)$, 1,8-cineol $(9,26 \%)$ e o $\gamma$-terpineno $(9,21 \%)$ como constituintes majoritários do óleo essencial de Lippia sidoides coletadas em Lavras/MG.

Quanto aos resultados de atividade antimicrobiana, é importante ressaltar que em função do teste controle, o "Tween 80", na dosagem utilizada, não interferiu na inibição do crescimento microbiano e queportanto os efeitos observados podem ser atribuídos ao óleo essencial de alecrim pimenta. Esta atividade antimicrobiana do óleo essencial de alecrim-pimenta já é comprovada e, os dados aqui encontrados corroboram com a literatura, porém dados são diferentes quanto a CIM e CBM encontrados, aos métodos de extração, à composição química do óleo, as cepas microbianas em teste e também ao teste utilizado para análise da atividade antimicrobiana. Estudos utilizando óleo essencial de alecrim pimenta na região Norte de Minas Gerais relataram atividade antimicrobiana efetiva. Andrade et. al. (2014) encontraram a concentração de $120 \mu \mathrm{L} / \mathrm{mL}$, eficiente em inibir o crescimento dos microrganismos Escherichia coli (ATCC 25922), Staphylococcus aureus (ATCC 25923) e Salmonella Cholerae suis (ATCC 10708). Queiroz et al. (2014) avaliaram a atividade antimicrobiana sobre cepas de $S$. aureus isoladas de alimentos de origem animal (carne, leite e queijo) e a CIM e CBM variaram de 15 a 240 $\mu \mathrm{l} / \mathrm{mL}$, dependendo da origem da cepa. Costa et al. (2011) encontram CBM de $20 \mu \mathrm{L} / \mathrm{mL}$ sobre cepas de $S$. aureus e $E$. coli isoladas de leite bovino e Castro et al. (2011), observaram alta atividade antimicrobiana sobre as bactérias $S$. aureus e E. coli isoladas de queijo artesanal com CIM de 13 $\mu \mathrm{L} / \mathrm{mL}$ para todas as bactérias testadas e a CBM foi de 25 $\mu \mathrm{L} / \mathrm{mL}$. O óleo utilizado por Andrade et al. (2014) e Queiroz et al. (2014) foram obtidos da mesma área que o utilizado neste experimento. Já Costa et al (2011) e Castro et al. (2011), utilizaram óleos essenciais provenientes de outras áreas da reserva nativa do ICA/UFMG.

As diferenças de sensibilidade de óleos essenciais descritas na literatura estão associadas também a metodologia adotada incluindo na extração dos compostos ativos (Othman et al. 2011, Radulović et al. 2013). Acredita-se que a atividade antimicrobiana é dependente de vários alvos de ação dos óleos na célula que podem potencializar a atividade (Negi 2012).

A presença dos compostos como timol, carvacrol, $\gamma$-terpineno e p-cimeno encontradas no óleo em estudo evidencia a presença de compostos com atividade antibacteriana para o óleo de alecrim-pimenta, conforme relatado por vários autores citados por Oliveira et al. (2014). A sinergia entre os compostos dos óleos essenciais na atividade antimicrobiana é citada na literatura devido ao fato de o óleo essencial ser uma mistura de compostos muito complexa. Andrade et al. (2014) citaram em seus resultados que possivelmente, a combinação de p-cimeno, em alta concentração, juntamente com o timol e carvacrol possam contribuir com a ação antimicrobiana do óleo de alecrim pimenta. Guimarães et al. (2014) concluíram que a atividade antimicrobiana de óleo essencial de alecrim pimenta foi superior à ação do composto carvacrol isoladamente, indicando que a ação conjunta dos componentes do óleo possam potencializar a atividade antimicrobiana, quando analisaram bactérias Gram positivas e Gram negativas. Veras et al. (2014) não encontraram diferenças significativas ao analisarem a atividade do óleo essencial e de timol isolado sobre bactérias Gram positivas. Deve-se considerar que os quimiotipos foram diferentes, conforme citados pelos autores.

Os dados descritos na literatura quanto à sensibilidade de Bactérias Gram negativas e Gram positivas ao óleo essencial de alecrim pimenta são controversos, no entanto uma gama considerável de microrganismos apresenta sensibilidade (Raut et al. 2014, Calo et al. 2015). Ainda que mecanicamente a ação dos óleos essenciais possa ser mais eficiente em bactérias Gram positivas devido à interação maior com os componentes hidrofóbicos da parede comparada com as Gram negativas, que possuem componentes hidrofílicos, alguns mecanismos ainda necessitam ser elucidados, devido à diversidade de resultados.

A ação primária dos óleos essenciais esta na desestabilização da parede celular. A hidrofibicidade relativa de carvacrol e timol permite a difusão através da matriz de polissacarídeo polar da parede bacteriana, enquanto que a propriedade hidrofóbica pode levar a interações específicas com a membrana bacteriana causando a dispersão das cadeias polipeptídicas da membrana celular, desestabilizando-a. A alteração no transporte de íons é, portanto prejudicial à célula microbiana. Ações relacionadas à desnaturação de proteínas citoplasmáticas e inativação de enzimas celulares pelos óleos essenciais também conduzem à morte da célula bacteriana (Burt et al. 2004, Saad et al. 2013, Raut et al. 2014, Calo et al. 2015).

0 efeito inibitório do óleo essencial de alecrim pimenta (Fig.2) observado neste estudo frente às cepas é confirmado pela inibição do crescimento microbiano em relação ao tempo zero, bem como ao controle, em que não foi utilizado óleo essencial. Estes índices de inibição são importantes, pois estão de acordo com os valores obtidos com a CIM para estas bactérias. A atividade antisséptica ocorreu de maneira mais eficiente nos tempos 5 minutos para $S$. aureus e 15 minutos para E. coli e Salmonella Choleraesuis e mantendo a inibição em menores índices inibitórios até 30 minutos e estes foram reduzindo até os 60 minutos após o contato. Estes dados são importantes, pois um bom desinfetante ou antisséptico é aquele que age em presença de matéria orgânica e em tempo rápido de ação. A diferença de resultados observada para as bactérias Gram positivas e a Gram negativas neste trabalho é decorrente do fato da cinética de inibição de crescimento ser dependente da estirpe bacteriana, das propriedades do antimicrobiano e sua concentração, resultando em diferentes tempos necessários para alcançar a fase exponencial de crescimento (Weiss et al. 2015).

Deve-se considerar que o efeito de doses sub-letais de óleos essenciais pode ser uma característica importante para uso em alimentos. Siroli et al. (2015) observaram alterações perceptíveis dos perfis de ácidos graxos e compostos voláteis na membrana celular de Literia monocytogenes, Salmonella Enteritidis e Escherichia coli, durante o crescimento na presença de diferentes concentrações sub-letais de óleos essenciais e de compostos puros carvacrol, timol, 
trans-2-hexenal e citral. Estes resultados podem contribuir para o compreensão dos mecanismos de resposta ao stress utilizado por diferentes microrganismos patogênicos frequentemente envolvido em doenças de origem alimentar, em relação à exposição a concentrações sub-letais antimicrobianos naturais.

Como a atividade dos óleos essenciais são dose-dependentes (Oliveira et al. 2014), maiores concentrações de óleo poderiam ter promovido maiores índices de inibição de crescimento das bactérias em estudo em menor tempo de ação. No entanto, deve-se considerar que além de forte odor que poderá acarretar em alteração das características sensoriais dos alimentos, e pode ocorrer toxicidade aguda e crônica, o que leva a indicação de testes com óleos em concentrações inibitórias e não bactericidas (Li et al. 2009). Esta perda de atividade dos óleos essenciais na maior parte pode ser associada a um fenômeno físico e pode ser explicado pela multiplicidade de interações moleculares que ocorrem quando os compostos são adicionados a um alimento estruturado composto por vários ingredientes (Weiss et al. 2015).

Não foram encontrados dados na literatura com avaliação do óleo essencial de alecrim-pimenta na presença de leite ou de outra matéria orgânica. Pesquisas com outros óleos essenciais que possuem carvacrol e timol e outros compostos majoritários apresentam resultados variáveis com tipo de alimento e tipo de bactérias (Cato et al. 2015). Os resultados aqui obtidos de redução do número médio de Log UFC de 2,18993 Log UFC para $S$. aureus no tempo de contato de 5 minutos, 2,343321 Log UFC para E. coli e 2,100343 Log UFC para Salmonella Choleraesuis, ambas no tempo 15 min evidenciam a ação do óleo na presença da matéria orgânica, ainda que tenha ocorrido redução do índice de inibição após 30 minutos de contato com o óleo.

A literatura descreve pesquisas com resultados satisfatórios quanto à ação de óleos essenciais provenientes de outras plantas em bactérias patogênicas presentes em derivados lácteos bem como a ação dos mesmos em culturas lácticas. Entre os óleos, apenas o óleo de orégano, que também possui carvacrol em sua composição, pode ser relacionado com os dados obtidos neste trabalho. Cattelan et al. (2013) utilizaram óleo essencial de orégano em queijo a $5 \%$ em relação ao volume de leite utilizado para preparo do queijo, levando à redução de 5 ciclos logarítimos em relação ao inicial em $24 \mathrm{~h}$ a $37^{\circ} \mathrm{C}$. Olmedo et al. (2013) observaram que os óleos essenciais de orégano e alecrim do campo demonstraram efeito protetor contra a oxidação e fermentação indesejável em "cream cheese" elevando o tempo de vida em prateleira dos produtos. Asensio et al. (2015) ao adicionarem óleo essencial de orégano no queijo cottage, observaram a redução do processo de deterioração da qualidade o que prolongou a vida de prateleira do produto. No entanto, em nenhum destes trabalhos foi citado o uso de alecrim-pimenta.

A dificuldade na padronização de testes que avaliem a atividade de óleos essenciais in vivo relaciona-se às interações entre particularidades das matrizes alimentares, características do microrganismo na presença do alimento e grupamentos químicos dos óleos essenciais (Bajpai et al. 2013). Diferentes grupos de matéria orgânica e componentes das matrizes alimentares como proteínas, gordura e carboidratos poderão interferir com a atividade do óleo essencial em teste (Pesavento et al. 2015). 0 pH e polaridade são importantes fatores que influenciam na eficácia antimicrobiana. Além disso, propriedades hidrofóbicas de algumas substâncias antimicrobianas podem dificultar a sua dissolução em água e limitar o seu uso em alimentos (Negi 2012).

\section{CONCLUSÕES}

0 óleo essencial de alecrim-pimenta com maior abundância de o-cimeno, seguido de carvacrol, $\gamma$-terpineno e timol apresentou atividade antisséptica na presença de leite bovino, com maiores índices de inibição de crescimento de Staphylococcus aureus no tempo de 5 minutos e 15 de minutos para Echerichia coli e Salmonella Choleraesuis, ao ser utilizado na concentração de $120 \mu \mathrm{L} / \mathrm{mL}$.

Os resultados obtidos demonstram que o óleo essencial de alecrim pimenta apresenta potencial para ser utilizado na elaboração de produtos antissépticos a serem utilizados, em particular, no controle de cepas patogênicas na produção leiteira.

Agradecimentos.- À FAPEMIG, CAPES, CNPq e UFMG-PRPq.

\section{REFERÊNCIAS}

Adams R.P. 2012. Identification of Essencial Oil Components by Gas Chromatography/Mass Spectroscopy. 4th ed. Allure, Allured Publishing Corp., USA.

Almeida A.C., Macedo Sobrinho E., Pinho L., Souza P.N.S., Martins E.R., Duarte E.R., Santos H.O., Brandi I.V., Cangussu A.V. \& Costa J.P.R. 2010. Toxicidade aguda dos extratos hidroalcoólicos das folhas de alecrim-pimenta, aroreira e barbatimão e do farelo da casca de pequi administrados por via intraperitoneal. Ciência Rural 40(1):200-204.

Andrade V.A., Almeida A.C., Souza D.S., Colen K.G.F., Macêdo A.A., Martins E.R., Fonseca F.S.A. \& Santos R.L. 2014. Antimicrobial activity and acute and chronic toxicity of the essential oil of Lippia origanoides. Pesq. Vet. Bras. 34(12):1153-1161.

APHA 2001. Compendium of Methods for the Microbiological Examination of Foods. 4th ed. American Public Health Association, Washington. $676 \mathrm{p}$.

Asensio C.M., Grosso N.R. \& Juliani H.R. 2015. Quality preservation of organic cottage cheese using oregano essential oils. LWT-Food Sci. Technol. 60(2):664-671.

Bajpai V.K., Sharma A. \& Baek K.H. 2013. Antibacterial mode of action of Cudrania tricuspidata fruit essential oil, affecting membrane permeability and surface characteristics of food-borne pathogens. Food Control 32(2):582-590.

Brasil 1993. Métodos de Análise Microbiológica para Alimentos. Portaria no. 101, de 17 de agosto de 1993. Ministério da Agricultura, Pecuária e Abastecimento. Diário Oficial da República Federativa do Brasil, Brasília, p.11937-11945, 17 de agosto de 1993, Seção I, 1993.

Brasil 2007. Resolução a Diretoria Colegiada no 14, de 28 de fevereiro de 2007. Aprova o Regulamento Técnico para Produtos Saneantes com Ação Antimicrobiana harmonizado no âmbito do Mercosul através da Resolução GMC nํ 50/06, que consta em anexo a presente Resolução. Disponível em <http://portal.anvisa.gov.br/wps/wcm/connect/a450e9004ba03d47b973bbaf8fded4db/RDC+14_2007.pdf?MOD=AJPERES> Acesso em 1 mai. 2013.

Burt S. 2004. Essential oils: their antibacterial properties and potential applications in foods: a review. Int. J. Food Microbiol. 94(3):223-253. 
Calo J.R., Grandall P.G., O’Bryan C.A. \& Ricke S.C. 2015. Essential oils as antimicrobials in food systems: a review. Food Control 54:111-119.

Castro C.E., Ribeiro J.M., Diniz T.T., Almeida A.C., Ferreira L.C., Martins E.R. \& Duarte E.R. 2011. Antimicrobial activity of Lippia sidoides Cham. (Verbenaceae) essential oil against Staphylococcus aureus and Escherichia coli. Revta Bras. Plantas Medic. 13(3):293-297.

Cattelan M.G., Castilhos M.B.M., Sales P.J.P. \& Hoffmann F.L. 2013. Antibacterial activity of oregano essential oil against foodborne pathogens. Nutr. Food Sci. 43(2):169-174.

CLSI 2012. Methods for Dilution Antimicrobial Susceptibility Tests for Bacteria that Grow Aerobically: approved standard. 9th ed. CLSI document M07-A9. Clinical and Laboratory Standards Institute, Wayne, PA. Disponível em <http://antimicrobianos.com.ar/ATB/wpcontent/ uploads/2012/11/03-CLSI-M07-A9-2012.pdf>

Costa J.P.R., Almeida A.C., Martins E.R., Rodrigues M.N., Santos C.A. \& Menezes I.R. 2011. Atividade antimicrobiana do óleo essencial de alecrim-pimenta e o extrato bruto seco do barbatimão diante de bactérias isoladas do leite. Biotemas 24(4):1-6.

Falkenberg M.B., Santos R.I. \& Simiões C.M.O. 2007. Introdução à análise fitoquímica, p.229-245. In: Simões C.M.O., Schenkel E.P., Gosmann G., Mello J.C.P., Mentz L.A. \& Petrovick P.R. Farmacognosia da Planta ao Medicamento. $6^{\mathrm{a}}$ ed. Editora da UFRGS, Porto Alegre, RS.

Guimarães L.G.L., Cardoso M.G., Souza R.M., Zacaroni A.B. \& Santos G.R. 2014. Óleo essencial de Lippia sidoides nativas de Minas Gerais: composição, estruturas secretoras e atividade antibacteriana. Revta Ciênc. Agron. Centro Ciênc. Agrárias 45(2):267-275.

Koketsu M. \& Gonçalves S.L. 1991. Óleos essenciais e sua extração por arraste em vapor. Documentos, Embrapa-CTAA, Rio de Janeiro. 24p.

Langoni H. 2013. Qualidade do leite: utopia sem um programa sério de monitoramento da ocorrência de mastite bovina. Pesq. Vet. Bras. 33(5):620-626.

Li F., Yunliang L., Xiao W., Yanling G. \& Daijie W. 2009. Preparative isolation and purification of capsaicinoids from Capsicum rutescens using high-speed counter-current chromatography. Separ. Pur. Tech. 64(3):304308.

Lima R.K., Cardoso M.G., Moraes J.C., Carvalho S.M., Rodrigues V.G. \& Guimaraes L.G.L. 2011. Chemical composition and fumigant effect of essential oil of Lippia sidoides Cham. and monoterpenes against Tenebriomolitor (L.) (Coleoptera: Tenebrionidae). Ciênc. Agrotec. 35(4):664-671.

Melo M.T.P., Ribeiro J.M., Meira M.R., Figueiredo L.S. \& Martins E.R. 2011. Teor de óleo essencial de alecrim-pimenta em função do horário de colheita. Ciência Rural 41(7):1166-1169.

Negi P.S. 2012. Plant extracts for the control of bacterial growth: Efficacy, stability and safety issues for food application. Intern. J. Food Microbiol. 156(1):7-17.

Oliveira M.L.M., Bezerra B.M.O., Leite L.O., Girão V.C.C. \& Nunes-Pinheiro D.C.S. 2014. Topical continuous use of Lippia sidoides Cham. essential oil induces cutaneous inflammatory response, but does not delay wound healing process. J. Ethn. 153(1):283-289.

Olmedo R.H., Nepote V. \& Grosso N.R. 2013. Preservation of sensory and chemical properties in flavoured cheese prepared with cream cheese base using orégano and Rosemary essential oils. LWT-Food Sci. Tech. 53(2):409-417.
Othman M., Loh H.S., Wiart C., Khoo T.J., Lim K.H. \& Ting K.N. 2011. Optimal methods for evaluating antimicrobial activities from plant extracts. J. Microb. Meth. 84(2):161-166.

Pesavento G., Calonico C., Bilia A.R., Barnabei M., Calesini F., Addona R., Mencarelli L., Carmagnini L., Martino M.C.D. \& Nostro A.L. 2015. Antibacterial activity of Oregano, Rosmarinus and Thymus essential oils against Staphylococcus aureus and Listeria monocytogenes in beef meatballs. Food Control 54:188-199.

Queiroz M.R.A., Almeida A.C., Andrade V.A., Lima T.S., Martins E.R., Figueiredo L.S. \& Careli R.T. 2014. Avaliação da atividade antibacteriana do óleo essencial de Lippia organoides frente à Staphylococcus sp. isolados de alimentos de origem animal. Revta Bras. Plantas Medic. 16(3):737743.

Radulović N.S., Mladenović M.Z., Blagojević P.D., Stojanović-Radić Z.Z., Ilic-Tomic T., Senerovic L. \& Nikodinovic-Runic J. 2013. Toxic essential oils. III. Identification and biological activity of new allylmethoxyphenyl esters from a Chamomile species (Anthemissegetalis Ten.). Food Chem. Toxicol. 62:554-565.

Raut J.S. \& Karuppayil S.M. 2014. A status review on the medicinal properties of essential oils. Ind. Crop. Prod. 62:250-264.

Saad N.Y., Muller C.D. \& Lobstein A. 2013. Major bioactivities and mechanism of action of essential oils and their components. Flavour Frag. J. 28(5):269-279.

Sampaio I.B.M. 2002. Estatística aplicada à experimentação animal. 2ª ed. Fundação de Estudo e Pesquisa em Medicina Veterinária e Zootecnia, Belo Horizonte. 265p.

Sarrazin S.L.F., Oliveira R.B., Barata L.E.S. \& Mourão R.H.V. 2012. Chemical composition and antimicrobial activity of the essential oil of Lippia grandis Schauer (Verbenaceae) from the western Amazon. Food Chem. 134(1):1474-1478.

Schuch L.F.D., Wiest J.M., Coimbra H.S., Prestes L.S., Toni L. \& Lemos J.S. 2008. Cinética da atividade antibacteriana in vitro de extratos naturais frente a microrganismos relacionados a mastite bovina. Ciênc. Anim. Bras. 9(1):161-169.

Siroli L., Patrignani F., Gardini F. \& Lanciotti R. 2015. Effects of sub-lethal concentrations of thyme and oregano essential oils, carvacrol, thymol, citral and trans-2-hexenal on membrane fatty acid composition and volatile molecule profile of Listeria monocytogenes, Escherichia coli and Salmonella enteritidis. Food Chem. 182(1):185-192

Teixeira M.L., Cardoso M.G., Figueiredo A.C.S., Moraes J.C., Assis F.A., Andrade J., Andrade J., Nelson D.L., Gomes M.S. \& Souza J.A. 2014. Essential oils from Lippia origanoides Kunth. and Menthaspicata L.: chemical composition, insecticidal and antioxidant activities. Am. J. Plant Sci. 5(9):1181-1190.

Van den Dool H. \& Kratz P.D. 1963. A generalization of the retention index system including linear temperature programmed gas-liquid partition chromatography. J. Chromatography 11:463-471. <http://dx.doi. org/10.1016/S0021-9673(01)80947-X>

Veras H.N.H., Rodrigues F.F.G., Botelho M.A., Menezes I.R.A., Coutinho H.D.M. \& Costa J.G.M. 2014. Antimicrobial effect of Lippia sidoides and thymol on Enterococcus faecalis biofilm of the bacterium isolated from root canals. Sci. World J. 14:1-5.

Weiss J., Loeffler M. \& Terjung N. 2015, The antimicrobial paradox: why preservatives loose activity in foods. Curr. Opin.. Food Sci. 4:69-75. 